\title{
Amino Acid Functionalization of Multi-Walled Carbon Nanotubes for Enhanced Apatite Formation and Biocompatibility
}

\author{
Ahmed Haroun $^{1}$, Zlatina Gospodinova ${ }^{2,3}$, Natalia Krasteva ${ }^{2}$ \\ ${ }^{1}$ Chemical Industries Research Division, National Research Centre, 12622 Dokki, Giza, Egypt. \\ ${ }^{2}$ Institute of Biophysics and Biomedical Engineering, Bulgarian Academy of Sci, Sofia, Bulgaria. \\ ${ }^{3}$ Institute of Plant Physiology and Genetics, Bulgarian Academy of Sci, Sofia, Bulgaria. \\ C Corresponding author. E-mail: haroun68_2000@yahoo.com
}

Received: Apr. 30, 202I; Accepted: Sep. 9, 202I; Published: Nov. 23, 2021

Citation: Ahmed Haroun, Zlatina Gospodinova, and Natalia Krasteva, Amino Acid Functionalization of Multi-Walled Carbon Nanotubes for Enhanced Apatite Formation and Biocompatibility. Nano Biomed. Eng., 202 I, I3(4): 380-393.

DOI: 10.5101/nbe.v13i4.p380-393.

\begin{abstract}
The limitation in bone tissue engineering is the lack of available natural or synthetic biomaterials to replace bone tissue under need. Carbon nanotubes have great potential as bone tissue scaffolds because of their remarkable mechanical and electrical properties combined with high aspect ratio. In this work, we demonstrated for the first time a novel approach based on the sol-gel technique for functionalization of multi-walled carbon nanotubes (MWCNTs) with two amino acids: L-arginine, $\mathrm{L}(+)$ Arg and L-aspargine, L(+) Asp. We have examined the effect of both functionalities on physicochemical properties of MWCNTs, cytotoxicity in osteosarcoma MG63 and normal fibroblastic BJ cells and the ability to induce nucleation and growth of hydroxyapatite (HA) crystals in vitro under physiological concentrations of $\mathrm{Ca}^{2+}$ and $\mathrm{PO}^{4+}$ (SBF). The scaffolds were characterized using Fourier transform infrared spectroscopy (FTIR-ATR), dynamic light scattering technique (DLS), X-ray diffraction (XRD), thermogravimetric analysis (TGA) and scanning electron microscopy (SEM). The results showed that both functionalized MWCNTs have a particle size of 269 and $411 \mathrm{~nm}$, a zeta potential of -12.8 and $-8.8 \mathrm{mV}$, respectively, high colloidal stability, enhanced biocompatibility, and enhanced formation of an apatite layer on the scaffolds surface in comparison to ox-MWCNTs. Altogether, the results confirmed the important role of the amino acids L(+) Arg and L(+) Asp in oxMWCNTs-based composites for bone tissue engineering applications.
\end{abstract}

Keywords: Carbon nanotubes, Amino acids, Nanocomposites, Biomaterials, In vitro cytotoxicity

\section{Introduction}

Carbon nanotubes (CNTs) have been used in different fields alone or as composites with other substances to develop highly functional materials. In particular, they hold great promise as scaffolds for bone regeneration. Despite many surprising results obtained for CNTs from the beginning of this research field, there are still tremendous opportunities to be explored substantial questions and risks to be resolved. So also vision and innovation are needed to elaborate changed conformation of CNTs and their conjugates with high effectiveness and safety for medicinal apply. Outstanding physical properties combined with a high aspect ratio and unique nanostructures make CNTs a potential candidate as reinforcement for many composites [1-3]. However, three main problems need to be solved in order to make the 
CNT generate the maximum effects in the biological system: (i) the dispersion of the CNTs in the aqueous media, (ii) high interfacial adhesion between the CNTs and the cellular system and (iii) high-risk assessment due to their diverse effects including cytotoxicity issue. To overcome these disadvantages, many attempts have been made to expand approaches for modification of CNTs, reproducible dispersions of the individual CNTs and elimination of their diverse effects [4, 5]. Functionalization of CNTs with biological molecules shows great potential for application in bioengineering and nanotechnology [6-9]. It is notified that pharmacological actions of CNTs coupled with therapeutical molecules are still not applied in humans and consequently, their clinical toxicity is also not evaluated. However, several reviews cover this topic extensively [10-19]. Work by Zhao et al. [20] focused on finding functional groups that could successfully attract calcium cations for the mineralization of hydroxyapatite (HA). If CNTs are incorporated into composite materials for medical applications, evidence of their bioactivity and toxicity is essential. The presence of CNTs in the composite may have no detrimental effects and could even enhance its bioactive properties [21-37]. A study by Georg et al. [38] tested the response of MWCNTs to human lung epithelial cells, osteoblast-like cells and primary osteoblast cells. They found that these cells attached and survived on MWCNTs. Zanello et al. [39] compared osteoblast proliferation and bone formation on functionalized and non-functionalized CNTs. They found that rat osteosarcoma ROS1712.8 cells grew best on the surfaces of prepared CNTs and neutrally charged polyethylene glycol-functionalized CNTs, while the lowest growth was found on oxidized MWCNTs. Their findings also suggested that the electrical activities of osteoblast membrane are maintained and $\mathrm{Ca}^{2+}$ channel functions are enhanced in cells grown on neutral CNTs. In terms of bone regeneration, CNTs can be considered osteoinductive material, which can elicit intracellular and extracellular cell responses at the material surface with low toxicity [40-43]. Finally, a recent in vivo study found no severe inflammatory response, such as necrosis, tissue degeneration, or neutrophil infiltration, after implanting oxidized MWCNTs in rats or dogs [44-47]. Amino acids could be used for functionalization of the hydroxyapatite nanoparticles (HAP) with synergistic effects on their properties as well as enhancement the protein adsorption [48, 49]. Tank et al. [50] have carried out the synthesized HAP nanoparticles using different amount of amino acid L-arginine to evaluate their anticipating biological activities. The formation of calcium-apatite on the surface of bioglass 45S5type in simulated body fluid (SBF) was confirmed by Kokubo et al. [51, 52]. According to these data, in 1991 it was reported that the formation of bonelike apatite on the material surface which reproduced in $\mathrm{SBF}$ is require for the material bonding to living bone in vivo. The characteristics of cell/material interaction are one of the most improtant phases. Also, using of in vitro culture models are being increased in the development of novel scaffolds [53]. Moreover, the cell/material interactions can be improved rather than that in the implanted foreign material in vivo [54]. On the other hand, the tripeptide (RGD) is one of the most known protein that promotes the animal cell attchment [55]. Besides, osteoblasts are almost interact with the biomaterials through focal contacts [56]. There are no studies previously reported on the use of Arg or Asp for functionalizing of oxidized MWCNTs using the sol-gel technique to the best of our knowledge. This work aims to develop novel scaffolds based on oxMWCNTs functionalized with amino acids (Arg or Asp) for bone tissue engineering. The physicochemical characterization by FTIR-ATR, XRD, SEM-EDX, XRD, TGA and DLS technique and in-vitro bone bioactivity after soaking in SBF at $37{ }^{\circ} \mathrm{C}$ for 7 days were investigated. Also, the in-vitro cytotoxicity against MG63 and BJ human osteosarcoma and normal fibroblast cell lines, respectively, using WST-1 and FDA assays, are presented in detail.

\section{Experimental}

\section{Materials}

Multi-walled carbon nanotubes (MWCNTs), carbon content $95 \%$, diameters 6-9 $\mathrm{nm} \times 5 \mu \mathrm{m}$ and tetra ethyl orthosilicate (TEOS) were obtained by Sigma-Aldrich. $\mathrm{L}(+)$ arginine (Arg), Mw 174.2 and $\mathrm{L}(+)$ asparagine (Asp), Mw 150.14 were purchased from Biobasic Canada Inc. and Merck Eurolab, respectively. All other chemicals and reagents were used as received.

\section{Methods}

\section{Oxidation and purification of MWCNTs}

Oxidized MWCNTs (ox-MWCNTs) were prepared by using olive oil. In a $500 \mathrm{~mL}$ flask, $1 \mathrm{~g}$ of crude MWCNTs was distributed in blended 30\% nitric acid and olive oil with a ratio $(3: 2 \mathrm{v} / \mathrm{v})$. The flask was then 
refluxed with continuous stirring at $1100{ }^{\circ} \mathrm{C}$ for $2 \mathrm{~h}$ to create ox-MWCNTs. The resulting material was collected under vacuum through filtration and then thoroughly washed with $500 \mathrm{~mL}$ of chloroform to remove the remaining oil [57]. The material collected was treated with ultrapure water until the filtrate was neutralized ( $\mathrm{pH} 7.0)$. The collected solid was vacuum dried for $12 \mathrm{~h}$ at $70{ }^{\circ} \mathrm{C}$ and kept for further investigation.

\section{Functionalization of ox-MWCNTs}

Functionalization of ox-MWCNTs using the solgel technique by hydrolysis and polycondensation of tetraethyl orthosilicate (TEOS) as a source of $\mathrm{SiO}_{2}$ containing HCL as a catalyst [58] in the presence of different amino acids (Arg or Asp) was employed as follows: The silicate solutions were stirred for $1 \mathrm{~h}$ with the molar ratio TEOS: $\mathrm{C}_{2} \mathrm{H}_{5} \mathrm{OH}: \mathrm{H}_{2} \mathrm{O}: \mathrm{HCl}$ (1:6:8:0.6). After 2 h, $100 \mathrm{mg}$ of ox-MWCNTs and $100 \mathrm{mg}$ of Arg or Asp were added and sonicated, accompanied by the addition of benzoin methyl ether (2.0 mmoL). In the sol-gel cycle, ox-MWCNTs and amino acid moieties were crosslinked, followed by a radical UV photoinitiated carboxylic group reaction. The sol was cast into plastic molds and gelled for 3 days at room temperature. The prepared scaffolds collected have been preserved for further study (Table 1).

Table 1 Chemical composition of the prepared scaffolds using sol-gel technique

\begin{tabular}{|c|c|c|c|c|}
\hline \multirow{2}{*}{ Sample } & \multicolumn{4}{|c|}{ Chemical compositions (Wt/ratio) } \\
\hline & Ox-MWCNTs & Arg & Asp & TEOS \\
\hline B1 & 1 & 1 & 0 & 1 \\
\hline B2 & 1 & 0 & 1 & 1 \\
\hline
\end{tabular}

\section{Characterization}

The prepared scaffolds were characterized using different analytical tools as follows: the chemical interactions were investigated by Bruker Fourier Transform Infrared Spectroscopy equipped with Attenuated Total Reflectance (FTIR-ATR) under the following conditions: scan resolution: $4 \mathrm{~cm}^{-1}$, scan rate: $2 \mathrm{~mm} / \mathrm{sec}$, number of scan: 32, range: 400$4000 \mathrm{~cm}^{-1}$ and mode: transmission. The particle size distribution analysis and zeta potential measurements were carried out at the run time: $2 \mathrm{~min}$, temperature: $25{ }^{\circ} \mathrm{C}$, solvent: water, concentration: $1 \mathrm{mg} / \mathrm{mL}$, using dynamic light scattering (DLS) technique by Malvern zetasizer instrument. The shapes and morphologies of the particles were investigated by Transmission Electron Microscope (TEM), Tokyo, Japan. Drops of the diluted preparations were deposited on a carboncoated copper grid, then left to dry at room temperature for $10 \mathrm{~min}$ before investigation. Thermal stability was carried out using thermogravimetric analysis (TGA) by SETaran-Instrumentation, France. Scanning electron micrographs (SEM) were recorded using JXA-840A Electron Probe Micro Analyzer JEOL-SEM, Japan, while the elemental analysis at the surface was carried out by energy dispersive $\mathrm{x}$-ray equipment connected to SEM. For SEM, the substrate was mounted on metal stubs and coated with gold-palladium with the thickness of deposit about $75 \AA$ at vacuum $7 \times 10^{-2}$ millibar and $2.4 \mathrm{kV}$ cathodic voltage before being examined using Polaron SEM Coating Instrument. The crystallinity of the different structures was carried out by the crushed powder sample, which subjected to intense X-rays of wavelength $1.54060 \mathrm{~A}^{\circ}\left(\mathrm{CuK}_{\alpha}\right)$ in a $2 \theta$ range $4^{\circ}$ $80^{\circ}$ at a scan rate of $2^{\circ} / \mathrm{min}$ and in step size [2 ${ }^{\circ} \mathrm{Th}$.] using PAnalytica Diffractometer System Empyrean, Netherland. The $(2 \theta)$ values were recorded directly and relative intensities of the diffraction peaks were estimated from X-ray diffraction spectra. The calcium element concentration was determined using Agilent 200 series AA Flam Atomic Absorption Spectroscopy.

\section{In vitro bone bioactivity study}

The prepared scaffolds were soaked in simulated body fluid (SBF), following the protocol of Kokubo et al. [59] at body temperature $37^{\circ} \mathrm{C}$ and $\mathrm{pH} 7.4$ for 7 days, then removed, rinsed using de-ionized water and dried for further investigations. After soaking, the material surface was examined via SEM and EDX to confirm the formation of ca- apatite layers. The bioactivity test was carried out three times for the sample to ensure the bioactivity behavior [60].

\section{In vitro cytotoxicity study Cells and culture}

Human osteosarcoma MG63 cells, and normal human BJ fibroblast cells obtained from American Type Culture Collection (ATCC, USA), were cultured in Dulbecco's modified Eagle's medium (DMEM, Sigma), supplemented with $10 \%$ (v/v) fetal bovine serum (FBS, Sigma) and 1\% penicillin/streptomycin at $37{ }^{\circ} \mathrm{C}$ and $5 \% \mathrm{CO}_{2}$. The culture medium was replaced every second day until $80 \%$ confluence was reached. The cells were harvested with trypsin/EDTA (Sigma) and were seeded at a density of $2 \times 10^{4}$ cells/ well in a 24-well plate for the FDA (Sigma) assay and a concentration of $1 \times 10^{4}$ cells/well in 96-well plates 
for WST-1 assay. Cells were cultivated at optimal conditions for $24 \mathrm{~h}$ before being exposed to increasing concentrations of the different prepared scaffolds. After the addition of the nanotubes, the cells were incubated for another $24 \mathrm{~h}$ then were processed according to the experiment>s protocol. Control cells were processed as tested samples in the absence of nanotubes. After 24 and $48 \mathrm{~h}$ the assays were carried out.

\section{FDA assay}

Fluorescein diacetate (FDA) assays were done to evaluate cell morphology alterations after 24 $\mathrm{h}$ exposure to tested materials. For this at the end of incubation, the cells were stained with $0.001 \%$ FDA (Sigma, Germany), dissolved in acetone for 2 min, rinsed several times with PBS and fluorescent micrographs were taken at magnification $10 \mathrm{X}$ using an inverted microscope Axiovert 25 (Carl Zeiss, Germany), equipped with a digital camera.

\section{Cell counting WST-1 assay}

Cell Counting WST-1 (WST-1, Roshe, Germany) was used to evaluate cell viability and cell proliferation rates after 24 and 48 h treatment, respectively, with the as-prepared nanotubes. It is a simple colorimetric assay based on the reduction of Dojindo's highly water-soluble tetrazolium salt, WST-1 in cells to give an orange-color formazan dye, which is soluble in the tissue culture media. The amount of the formazan dye generated by the activities of dehydrogenases in cells, is directly proportional to the number of living cells. At the end of incubation, the cell culture medium was replaced with $1 \mathrm{~mL}$ fresh one and $10 \mu \mathrm{L}$ of WST-1 reagent was added to each well. After $4 \mathrm{~h}$ incubation at $37^{\circ} \mathrm{C}$, at dark, the amount of the colored product of the reaction was measured spectrophotometrically at $\lambda$ $=450 \mathrm{~nm}$.

\section{Results and Discussion}

\section{Physicochemical characterization}

The chemical interaction between ox-MWCNTs and different amino acids (Arg and Asp) using the sol-gel technique was confirmed using FTIR-ATR spectroscopy. FTIR spectra of the as-prepared samples and the spectral data are shown in Fig. 1 and Table 2, respectively. In contrast with the pure amino acids (Arg and Asp) and ox-MWCNTs, the obtained scaffolds (B1: MWCNTs/TEOS/Arg and B2: MWCNTs/TEOS/Asp) showed clear evidence of the desired functionalities. Characteristic bands of absorption for the carboxylic

\begin{tabular}{cc} 
Table 2 FTIR-ATR interpretation of the prepared scaffolds \\
\hline Peak $\left(\mathrm{cm}^{-1}\right)$ & Interpretation \\
\hline $3079-3451$ & O-H (str) \\
$2856-2941$ & C-H ( str, Alkyl) \\
1775 & $-\mathrm{C}=\mathrm{O}$ (str, ester) \\
1633 & $\mathrm{C}=\mathrm{O}$ (str) \\
$1530-1608$ & N-H (bending) \\
$1417-1436$ & $\mathrm{C}-\mathrm{H}$ (in-plane pending) \\
$1305-1376$ & $\mathrm{C}-\mathrm{N}-\mathrm{C}$ (axial str) \\
$1079-1160$ & Si-O-Si (str) \\
$808-894$ & Si-C (str) \\
$665-755$ & Si-OH (str) \\
$457-630$ & C-O-C (str) \\
\hline
\end{tabular}

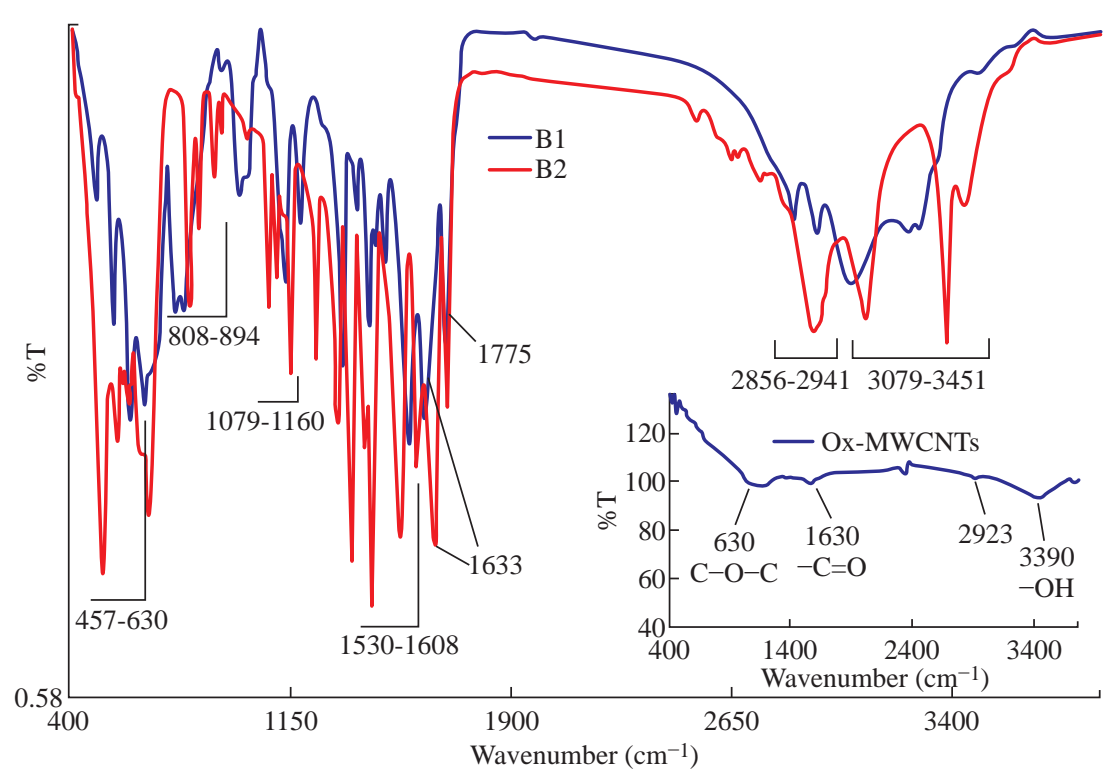

Fig. 1 FTIR-ATR spectra of the prepared scaffolds: (B1) MWNTs/arginine and (B2) MWCNTs/asparagine in comparison with the ox-MWCNTs. 
groups $(\mathrm{C}=\mathrm{O})$, stretching vibrations of the imide carbonyl groups and $\mathrm{N}-\mathrm{H}$ bending vibration appeared at 1633,1775 and (1530-1608) $\mathrm{cm}^{-1}$, respectively. It is expected that these sharp peaks resulted from the Arg or Asp groups that were attached to the ox-MWCNTs. Besides, the $\mathrm{N}-\mathrm{H}$ amide groups that were observed on the functionalized samples (B1 and B2) appeared at (1305-1376) $\mathrm{cm}^{-1}$ which is attributed to the C-N-C axial stretching bonds could indicate that the amidation reactions occurred between the amino groups of Arg or Asp and the carboxyl groups on the surface of the oxMWCNTs. The characteristic broad peaks in the range of (3079-3451) cm ${ }^{-1}$ which is assigned to $\mathrm{O}-\mathrm{H}$ bonds' stretching vibration, indicating that the amino acids have been successfully attached to the ox-MWCNTs. The peaks around (2856-2941) and (1417-1436) $\mathrm{cm}^{-1}$ are also assigned to the stretching and in-plane bending vibrations of the alkyl groups' $\mathrm{C}-\mathrm{H}$ bonds, respectively. While, the small peak around $2923 \mathrm{~cm}^{-1}$ was ascribed to aliphatic $\mathrm{sp}^{3} \mathrm{C}-\mathrm{H}$ of ox-MWCNTs [61]. The MWCNTs that were oxidized and then silanized during sol-gel preparation showed distinctive absorption bands at (1079-1160), (808-894) and (457630) $\mathrm{cm}^{-1}$, characteristic of $\mathrm{Si}-\mathrm{O}-\mathrm{Si}, \mathrm{Si}-\mathrm{C}\left(\mathrm{Si}-\mathrm{CH}_{2}\right)$ and C-O-C functional groups, respectively. Besides, a weak band at (667-755) $\mathrm{cm}^{-1}$ associated with $\mathrm{Si}-\mathrm{OH}$ also appears as expected from the TEOS's hydrolysis $[62,63]$. It can be concluded from the FTIR-ATR spectra that the pure amino acids (Arg or Asp) could be covalently attached to the surface of the functionalized MWCNTs obtaining new scaffolds (B1 and B2) via sol-gel technique.

XRD examined the structure of the functionalized ox-MWCNTs, and the resultant curves are illustrated in Fig. 2. In pure amino acids (Arg and Asp) XRD patterns, the crystalline structures were observed as previously reported $[64,65]$. It was attributed to the existence of a high degree of hydrogen bonding between hydroxyl and carboxylic groups. Moreover, the pure silica XRD patterns in the range $2 \theta=10$ 17 showed that the silica has an amorphous structure. Similarly, the ox-MWCNTs XRD patterns revealed that it has an amorphous phase [66]. For ox-MWCNTs, two peaks at $2 \theta=25.4$ and 42.5 typically correspond to the interlayer spacing $\mathrm{d}_{(002)}$ and $\mathrm{d}_{(100)}$ reflection peaks, respectively [67]. Therefore, the crystalline structure of the functionalized ox-MWCNTs with Arg and Asp was considered the same as that of the salinized oxMWCNTs, besides new patterns according to the different amino acids.

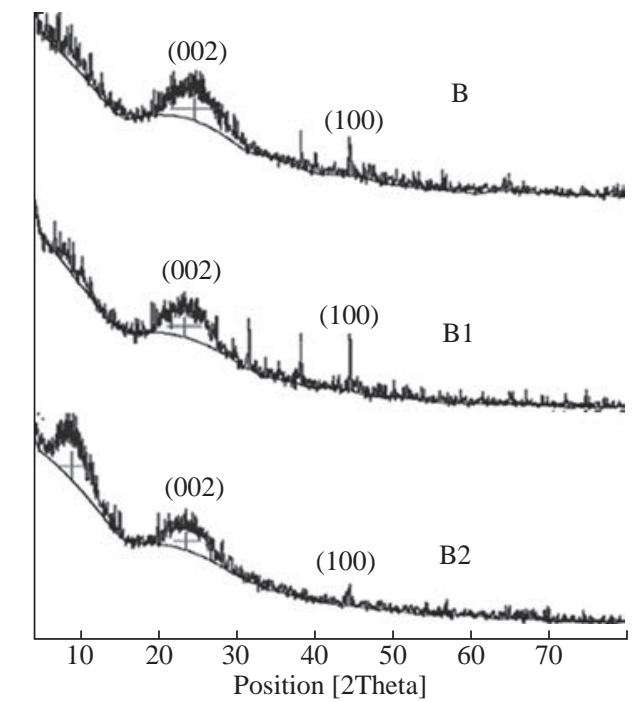

Fig. 2 XRD patterns of the scaffolds (B1) MWNTs/arginine and (B2) MWCNTs/asparagine in comparison with the oxMWCNTS/TEOS.

Table 3 shows the particle size distribution analysis of the as-prepared scaffolds by correlation with intensity using DLS technique. It can be noticed that the particle size of the functionalized MWCNTs decreases to $269 \pm 31.9$ and $411 \pm 61.1 \mathrm{~nm}$ in the case of Arg and Asp, with a polydispersity index (PDI) around $0.83-0.81$, respectively. While the average size of the ox-MWCNTs was $495 \pm 63.2 \mathrm{~nm}$ and PDI $=0.75$. Probably this is due to the covalent attachment of both amino acids to the sidewalls of the ox-MWCNTs/ TEOS matrix. It can also be concluded that the reaction of both amino acids with the salinized MWCNTs using the sol-gel technique was taken place via covalent bonding rather than adsorption. This is in accordance with our previous study that reported on the effect of ox-MWCNTs on the particle size of the immobilized L-asparaginase enzyme [68]. The zeta potential was measured to point out the effect of the different functional groups of Arg or Asp on the surface charge density of the functionalized ox-MWCNTs. Table 3 shows the zeta potential data at a constant $\mathrm{pH}$ (7.4). Zeta potential was found to be negative for all studied nanotubes as in the case of B1 and B2, the values increase to -12.8 and $-8.8 \mathrm{mV}$, respectively, in

Table 3 Particle size and zeta potential measurements of the prepared scaffolds using the DLS technique

\begin{tabular}{cccc}
\hline Sample & $\begin{array}{c}\text { Particle size } \\
(\mathrm{d} / \mathrm{nm})\end{array}$ & $\begin{array}{c}\text { Zeta potential } \\
(\mathrm{mV})\end{array}$ & Variance (PDI) \\
\hline Ox-MWCNTs & $495 \pm 36.2$ & -21.8 & 0.75 \\
B1 & $269 \pm 31.9$ & -12.8 & 0.83 \\
B2 & $411 \pm 61.1$ & -8.8 & 0.81 \\
\hline
\end{tabular}




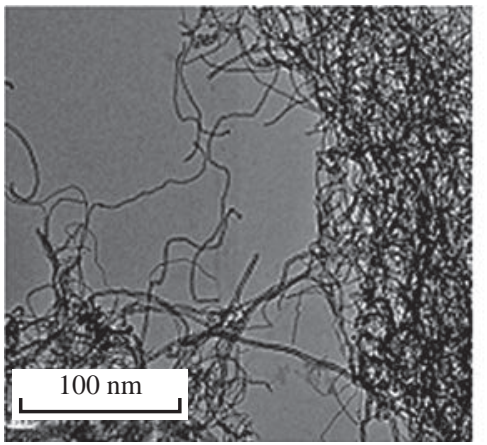

Crude MWCNTs

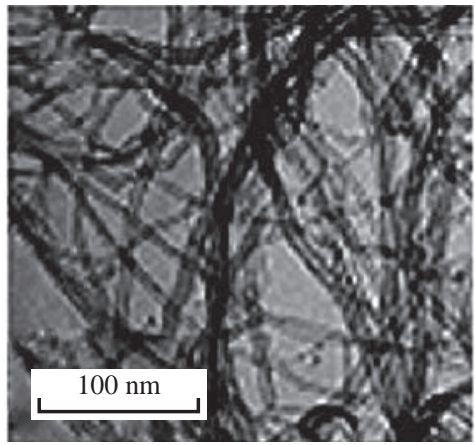

Ox-MWCNTs

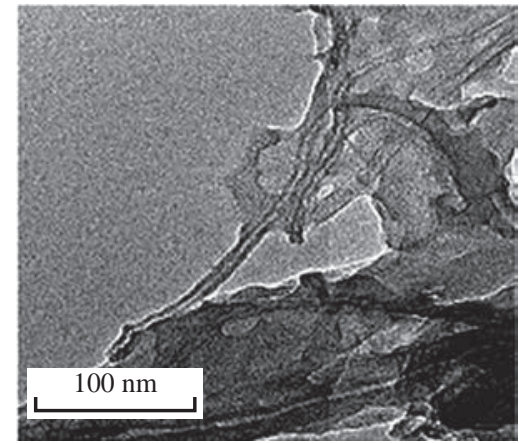

MWCNTs/TEOS

Fig. 3 TEM images of the functionalized MWCNTs with TEOS in comparison with crude and ox-MWCNTs.

comparison to ox-MWCNTs $(-21.8 \mathrm{mV})$. This reveals a high charge density with a relatively lower free carboxyl group at the surface of the ox-MWCNTs. The negative zeta potential may be attributed to carboxylic groups in the ox-MWCNTs, which carry predominantly free carboxylic acid groups. As previously reported, the zeta potential decreases with increasing the $\mathrm{pH}$ and becomes negative at high $\mathrm{pH}$ values [69]. Also, the above observations can be attributed to the presence of a high amount of carboxylic groups and the coexistence of other negatively charged compounds. Fig. 3 shows TEM images of the salinized MWCNTs with TEOS using the sol-gel technique compared to the crude and ox-MWCNTs. It can be noticed that the length of the crude MWCNTs was several tens of microns, and the diameter was approximately $10-30 \mathrm{~nm}$. The previous work [70] reported that the aggregation of chemically modified MWCNTs was determined to be less than that of crude MWCNTs because the carboxylic acid increased their polarity. Consequently, the functionalization of MWCNTs with carboxylic acid, amino and hydroxyl groups during the sol-gel process, exhibited nanohybrid materials with a network structure of silica among the MWCNTs. TEM images also revealed that the ox-MWCNTs had a smoothsided wall with a spaghetti-like morphology and were severely agglomerated. After functionalization with TEOS (weight ratio 1:1), tubes were less bundled and isolated individually. It can be concluded that ox-MWCNTs were incorporated into silica particles to prevent the agglomeration of the nanofibers and increase the surface area.

TGA is a technique widely used to determine surface functionalization and thermal stability of materials based on weight loss or gained as a function of temperature, and their thermal properties can easily plot into a simple thermogram. In general, a TGA thermogram is divided into few stages of decomposition: (i) the first stage is related to the release of water moisture; (ii) the subsequent stages are associated with the structural decomposition of polymers and finally combustion of the remaining material. Fig. 4 shows TGA curves of the prepared scaffolds (B1: MWCNTs/TEOS/Arg and B2: MWCNTs/TEOS/Asp) compared to the functionalized ox-MWCNTs with TEOS (B). Besides, the TGA data (weight loss \% at different temperatures ${ }^{\circ} \mathrm{C}$ ) are shown in Table 4.

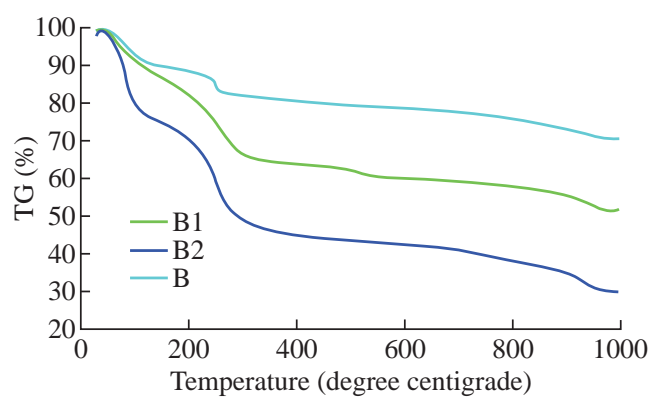

Fig. 4 TGA diagrams of the scaffolds (B1) MWNTs/arginine and (B2) MWCNTs/asparagine in comparison with (B) the oxMWCNTS/TEOS (B).

Table 4 TGA data (weight loss\%) of the scaffolds (B1: MWNTs/ arginine) and B2: MWCNTs/asparagine) in comparison with B (ox-MWCNTs/TEOS) at different temperatures

\begin{tabular}{cccc}
\hline \multirow{2}{*}{ Sample } & \multicolumn{3}{c}{ Weight loss (\%) at different temperatures $\left({ }^{\circ} \mathrm{C}\right)$} \\
\cline { 2 - 4 } & $30-160$ & $160-343$ & Up to 343 \\
\hline B & 11.2 & 23.2 & 34.4 \\
B1 & 25.5 & 43.9 & 69.4 \\
B2 & 9.6 & 44.0 & 53.6 \\
\hline
\end{tabular}

The ox-MWCNT demonstrated relatively high thermal stability due to its excellent temperature resistance, generating a total weight loss of about $19.12 \%$. It is mainly contributed by the decomposition of free carboxyl and hydroxyl groups present on the surface of the nanotubes. Furthermore, the carboxyl groups grafted on the surfaces of MWCNT during 
the oxidation process reacted to form a network of hexagonal hydrogen bonds and subsequently improved the degradation s activation energy of MWCNT [71]. In general, it was found that all samples (B1 and B2) demonstrated a different thermal property when compared to B sample. It can also be noticed that the thermal stability of the prepared scaffolds B1 and B2 was decreased after incorporating the different amino acids (Arg and Asp, respectively) relative to that of the salinized ox-MWCNTs (B) sample. This may be due to the presence of many hydrophilic moieties inside the composite. In other words, the weight loss (\%) of the prepared scaffolds up to $344{ }^{\circ} \mathrm{C}$ was around 69.4 and $53.6 \%$, in the case of $\mathrm{B} 1$ and $\mathrm{B} 2$, respectively, relative to that of the B sample (34.4\%).

\section{In vitro bone bioactivity evaluation}

The scaffolds (nanotubes) were explored post soaking for 7 days after their withdrawal from SBF by SEM-EDX to affirm the apatite layer's arrangement onto the composite surface (scaffolds). The interaction between the surface of composites and calcium phosphate arrangment may be dependable for the apatite nucleation. This hypothesis is backed by SEM preception at tall amplification, which appears a near affiliation of apatite with the surface of composites. It has been demonstrated that $\mathrm{RCOO}^{-}$groups present in Arg or Asp at pH greater than 7.0 are largely ionized and offer binding sites for $\mathrm{Ca}^{2+}[72,73]$. The ion complexes further interact with $\left(\mathrm{PO}_{4}\right)^{3-}$ ions due to the supersaturation effects, forming critical size nuclei and subsequent growth of apatite particles occurs [74]. According to our previous study [75], the changes in size and aspect ratio of the crystals clearly proved that the homogenous crystallization of hydroxyapatite (HA) on nanoparticles' surface is inhibited. The composites might have a solid partiality to both calcium and phosphate. The interaction between the surface of composites and calcium phosphate solution may be dependable for the apatite nucleation. In other words, SEM perception of apatite arrangement on the coating after the scaffolds were soaked in
SBF appears a thick apatite layer arrangement after immersing in for 7 days as shown in Fig. 5. A layer comprising of spongy structure is shaped on the full surface for the composites B1 and B2 relative to oxMWCNTs characterizing the network of the apatite layer that demonstrated the impact of amino acids on the improvement of apatite arrangement. Beside, the multiplication and development of bone-like apatite on the surface of the composites were showed. SEMmicrographs moreover appeared the appearance of huge crystal-like shapes containing diminutive pores aggregated to each other, which advantage bone in development. The island-like highlights that showed up after the soaking in SBF were assemblies of tiny crystals formed on the surfaces of the composites. The number of apatite islands expanded obviously with the presence of amino acids. From Table 5, it can be noticed that EDX spectrum of ox-MWCNTs shows a large peak of high intensity corresponding to the presence of carbon from organic phase and small peaks of low intensity corresponding to the trace elements $\mathrm{O}, \mathrm{Na} \mathrm{Cl}$ from the inorganic phase. While, after functionalization of ox-MWCNTs, large peaks were observed corresponding to Si from the condensation process of TEOS during sol-gel preparation and the other peaks corresponding to the calcium phosphate inorganic component. The in vitro test proved that the presence of the different amino acids (Arg and Asp) in the composites B1 and B2, respectively, indicated high chemical bioactivity in SBF whereas the absence of the amino acids in the composites exhibited slight chemical bioactivity post immersion, which SEM reveals. These results proved that the addition of certain amounts of Arg or Asp to the salinized MWCNTs could be significantly effective, as investigated by their accelerated bioactivity. Moreover, the bioactive mechanism of composites is rapidly enhanced and positive response can be obtained. It was reported that when most of the bioactive materials are soaked in SBF, a new calcium phosphate phase, which is similar to the calcium-deficient apatite layer, is formed in the living body (bone-like apatite layer)

Table 5 Elemental analysis of the prepared scaffolds after soaking in SBF for 7 days at $37^{\circ} \mathrm{C}$ in comparison with ox-MWCNTs using EDX technique

\begin{tabular}{|c|c|c|c|c|c|c|}
\hline \multirow{2}{*}{ Sample } & \multicolumn{6}{|c|}{ Elemental analysis (Wt\%) } \\
\hline & $\mathrm{Ca}$ & $\mathrm{Si}$ & $\mathrm{C}$ & $\mathrm{O}$ & $\mathrm{Cl}$ & $\mathrm{Na}$ \\
\hline Ox-MWCNTs & 0.13 & 0.0 & 72.93 & 19.38 & 1.23 & 6.33 \\
\hline B1 & 0.94 & 33.11 & 36.301 & 25.78 & 1.54 & 2.33 \\
\hline B2 & 1.02 & 34.32 & 35.52 & 24.28 & 1.43 & 3.43 \\
\hline
\end{tabular}



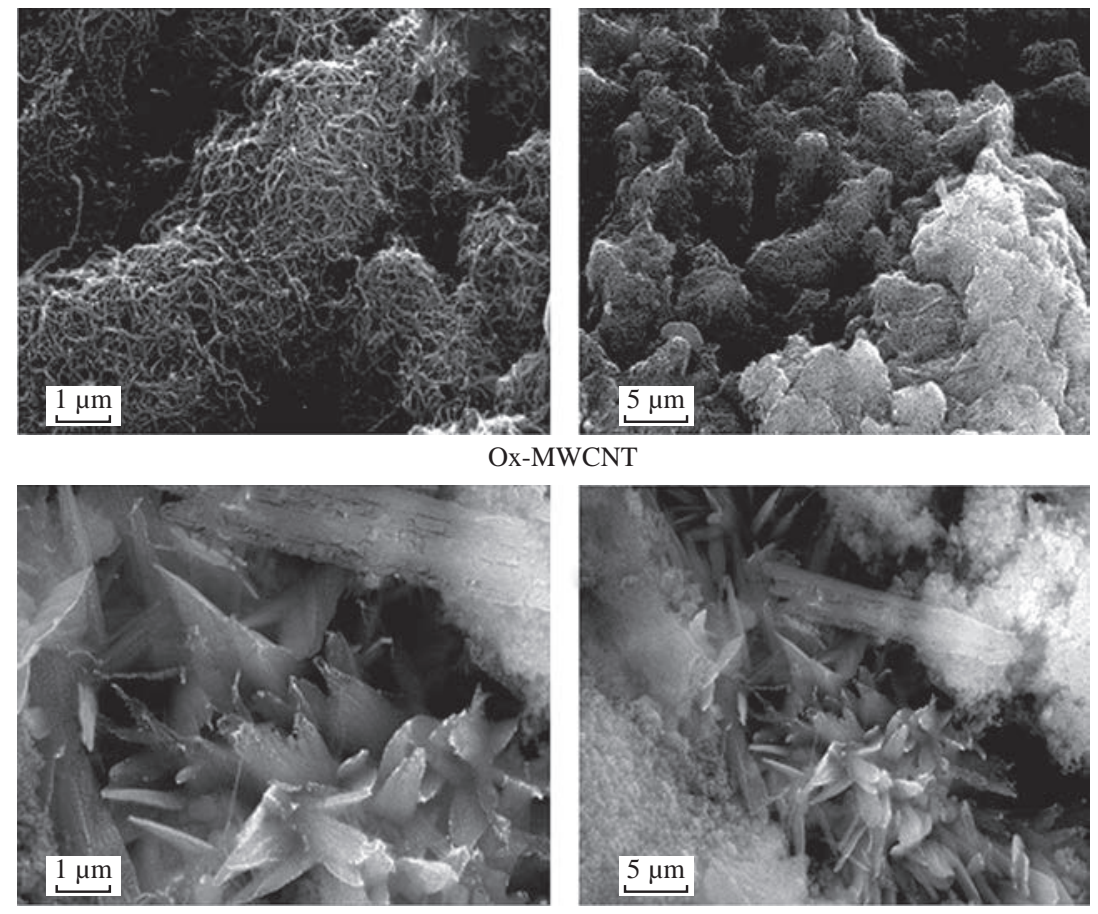

B1
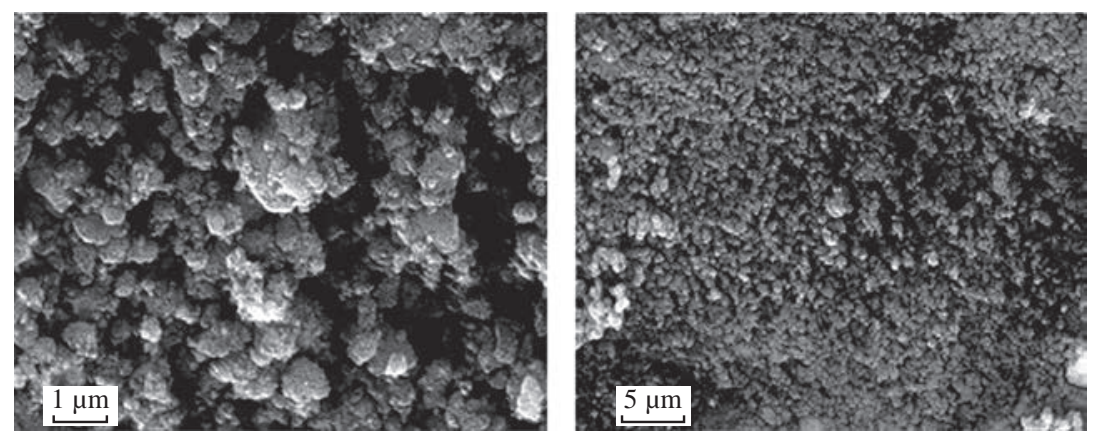

B2

Fig. 5 SEM-micrographs of the prepared scaffolds after soaking in SBF for 7 days at $37{ }^{\circ} \mathrm{C}$ in comparison with ox-MWCNTs at different magnifications $100 \times 10^{3} \times(1 \mu \mathrm{m})$ and $25 \times 10^{3} \times(5 \mu \mathrm{m})$.

on their surfaces. This phenomenon is known as the biomimetic formation of apatite layer forming new materials, which can provide information on their chemical properties in the development of biomaterials [76, 77]. Hench [78] reported a good correlation between in vitro bone-like apatite formation from SBF and in vivo bone-like apatite (calcium phosphate) formation needed to secure bone bonding. It can be concluded that the surface of the scaffolds included the different amino acids (Arg or Asp) could stimulate bone-like apatite deposition on the surface of bioactive glass by the uptake of calcium and phosphate from body fluid. Hence, the chemical bonding between the surface of those composites and bone is expected to be achieved through the apatite in the same way that bioactive materials bond with the bone. These expectations are currently under investigation in vivo.

On the other hand, Fig. 6 shows calcium element concentrations of SBF after soaking off the scaffolds measured by atomic absorption spectroscopy. The calcium concentration was gradually decreased with an increase in the soaking time. At the initial stage,

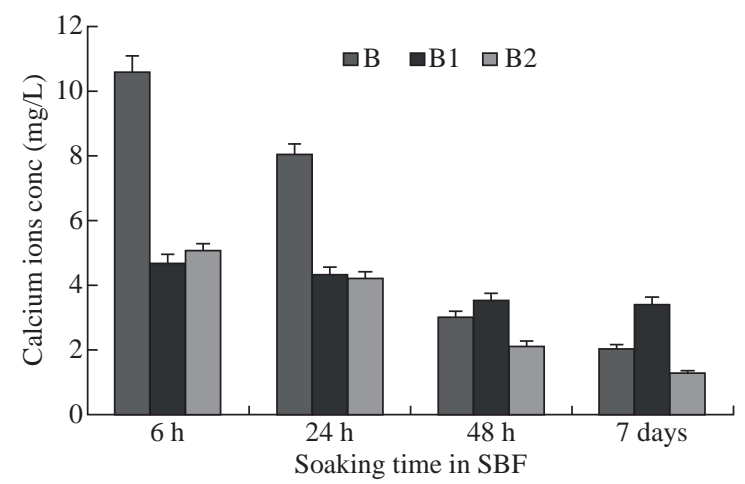

Fig. 6 Changes in calcium element concentrations of (B1) and (B2) SBF after soaking of the scaffolds in comparison with (B) the ox-MWCNTs/TEOS measured by atomic absrption spectroscopy. 
the Ca was dramatically decreaed in both scaffolds B1 and B2 compared with B sample. This may be due to the presence of both amino acid moieties in the scaffolds that enhanced the Ca uptake from SBF after their incubation. In addition, B2 was more accelerated the ca uptake than that the other one. This may be due to the decrease in the degree of supersaturation of the fluid with respect to the apatite. This result was in agreement with the elemental analysis using EDX and the previous data reported by Miyazaki et al. [79].

\section{In vitro cytotoxicity evaluation}

Although MWCNTs have great application potential in tissue engineering, their toxicological effects cannot be ignored since it represents a big challenge for the clinical applications. The toxicity of CNTs needs to be well characterized and accurately identified on different cell lines and tested in vitro and in vivo. A wide range of in vitro studies has revealed the mechanisms by which CNTs can lead to cell toxicity, including
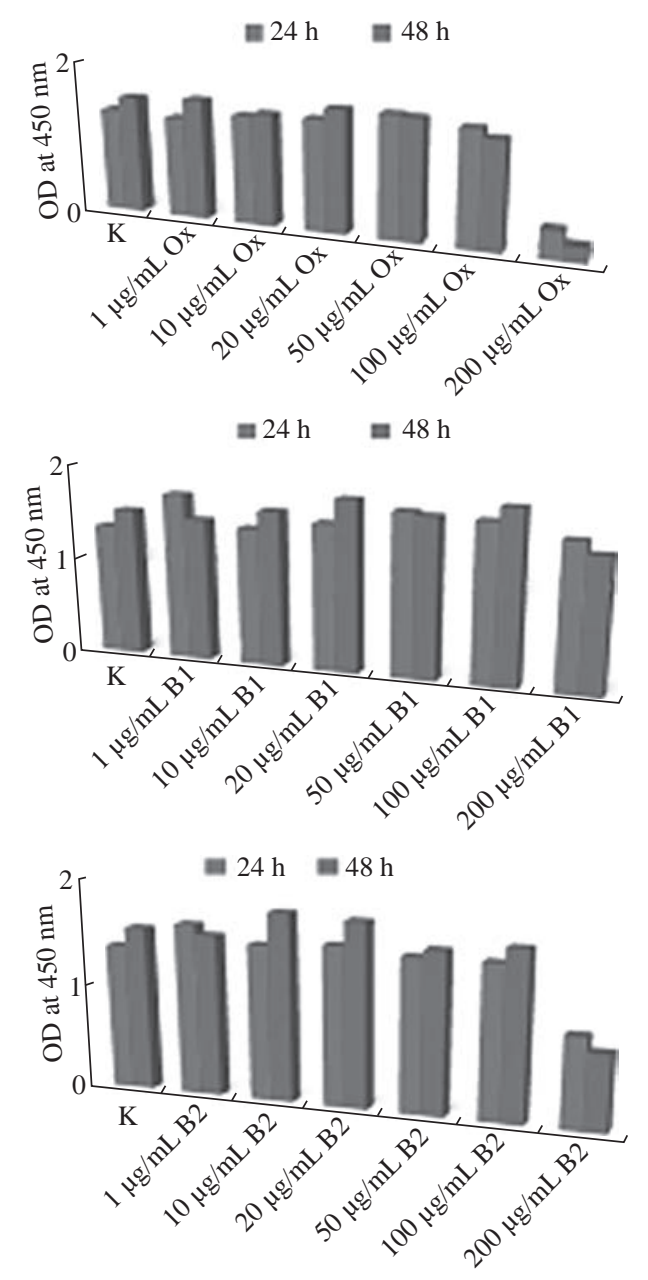

Fig. 7 Viability and proliferation rates of human osteosarcoma MG36 cells after cell culture with the prepared scaffolds: (B1) MWNTs/arginine and (B2) MWCNTs/asparagine in comparison with ox-MWCNTs using WST-1 assay. oxidative stress and mitochondrial dysfunction [8083]. Cytotoxicity of MWCNTs is influenced by many factors, e.g., the size, surface area, agglomeration, synthesis method, and impurities [84]. The potential cytotoxic effects of CNTs can be avoided by changing the method of synthesis and purification or proper modification of the surface of CNTs. Functionalization with carboxyl or amino groups, for instance, has been shown to mitigate the toxic effects of pristine MWCNT in macrophages [85]. In this work, we have functionalized ox-MWCNTs with two amino acids, namely Asp and Arg, and have evaluated their potential cytotoxicity on two cell lines: osteosarcoma, MG63 and fibroblastic, BJ. For this aim, we have monitor cell morphology, viability, and growth as essential signs of the cells' physiological state. We chose the osteoblast-like cells MG63 and normal fibroblast BJ cell to address bone toxicity of MWCNT since those cells are well characterized cellular models and stable
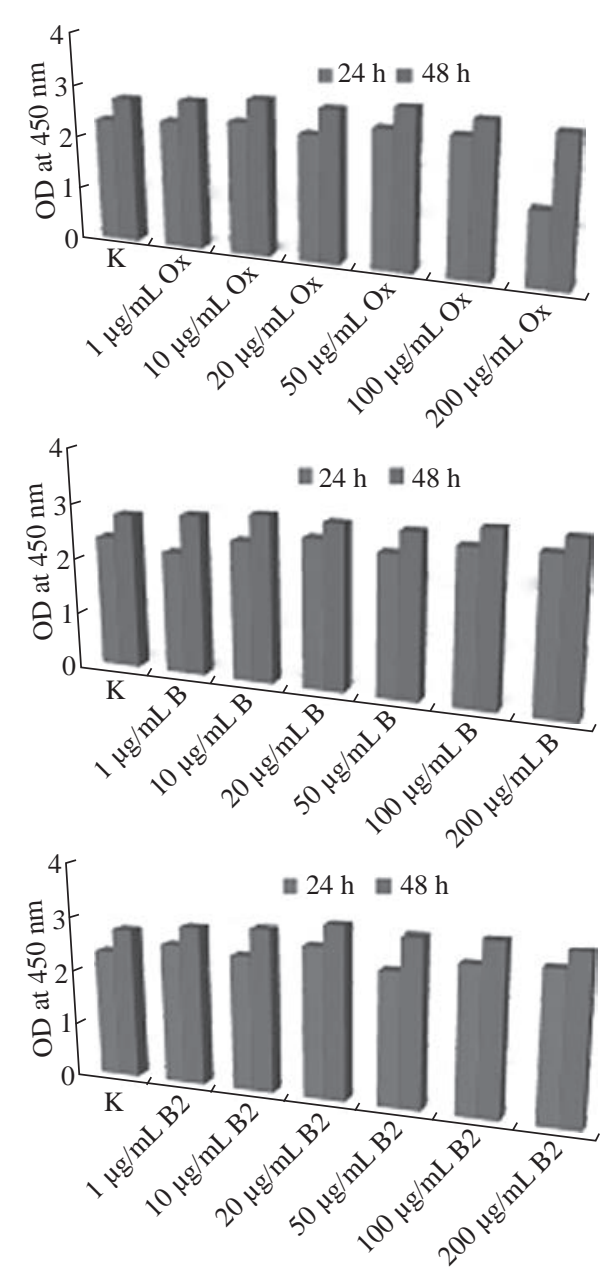

Fig. 8 Viability and proliferation rates of human fibroblastic BJ cells after cell culture with the prepared scaffolds: (B1) MWNTs/arginine and (B2) MWCNTs/asparagine in comparison with ox-MWCNTs using WST-1 assay. 
cell lines suitable for investigating in vitro cytotoxic potential of nanomaterials. Our intention here was to assess whether these MWCNT formulations were cytotoxic irrespective of the cell line's type and origin. Further, cell viability and growth were evaluated by WST-1 assay, following 24- and $48 \mathrm{~h}$ exposure to MWCNTs and the results are shown in Figs. 7 and 8. In general, the results from the 24 hours-MWCNTs exposure confirmed the morphological observation. A reduction in cell viability was detected in BJ cells treated with $200 \mu \mathrm{g} / \mathrm{mL}$ ox-MWCNTs. Conversely, the concentrations between 1 and $100 \mu \mathrm{g} / \mathrm{mL}$ even stimulated cell viability as can be concluded from the increased number of viable cells compared to the untreated control. At the $48 \mathrm{~h}$ significant difference in cell proliferation rates between all MWCNTs formulations with different concentrations was not found. OD values were slightly increased compared to the control demonstrated rather a positive effect of asprepared MWCNTs on cell proliferation and indicating that MWCNTs had relatively good biocompatibility. Studies on cellular and molecular mechanisms showed
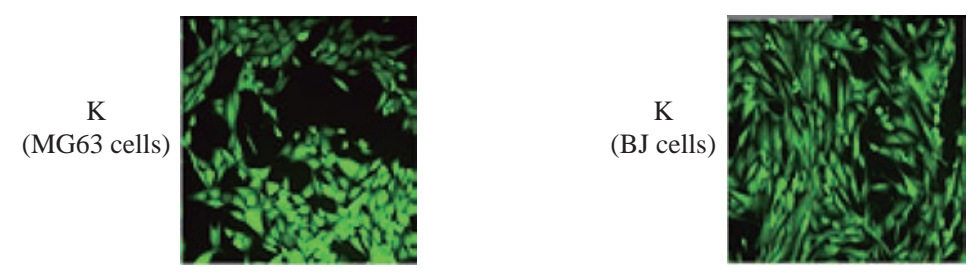

(a)
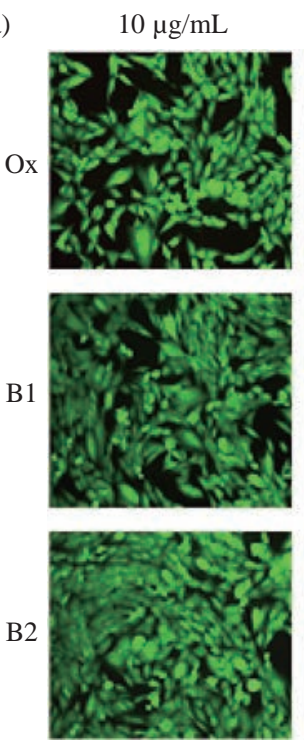

(b)
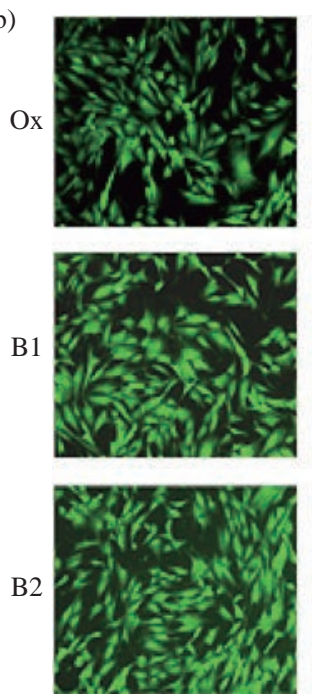

$20 \mu \mathrm{g} / \mathrm{mL}$
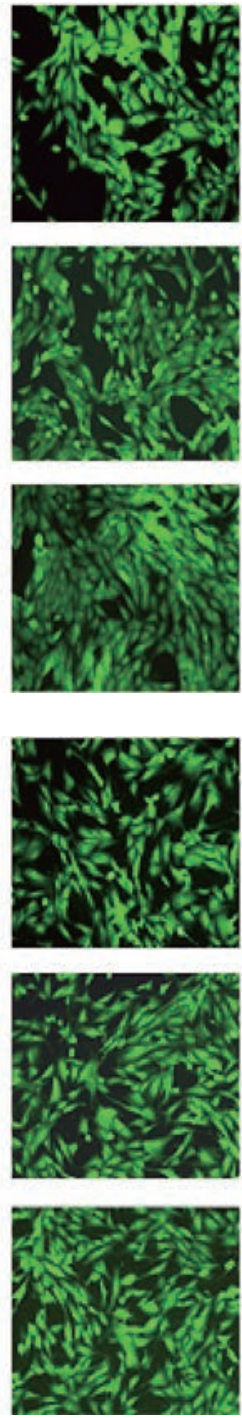

$50 \mu \mathrm{g} / \mathrm{mL}$
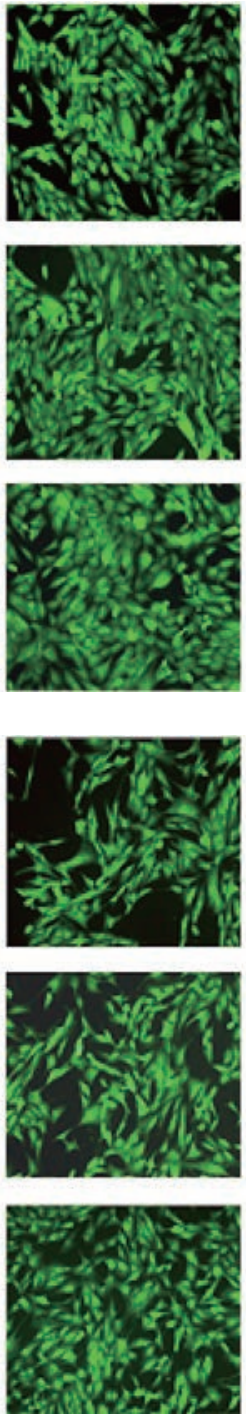

$100 \mu \mathrm{g} / \mathrm{mL}$
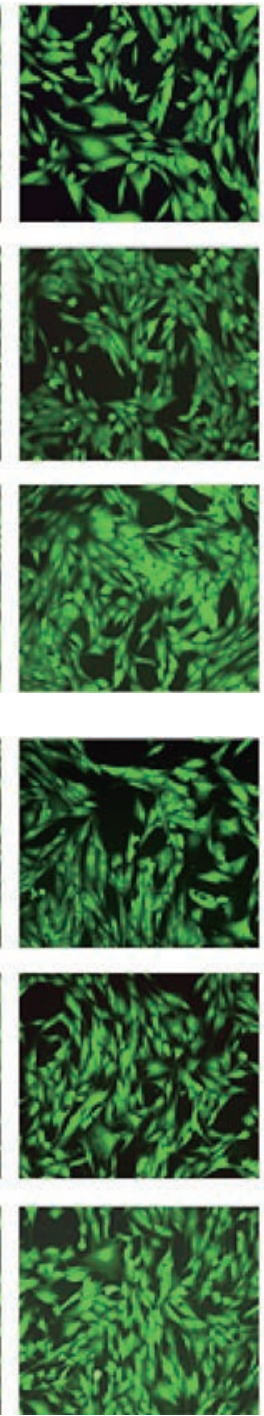

$200 \mu \mathrm{g} / \mathrm{mL}$
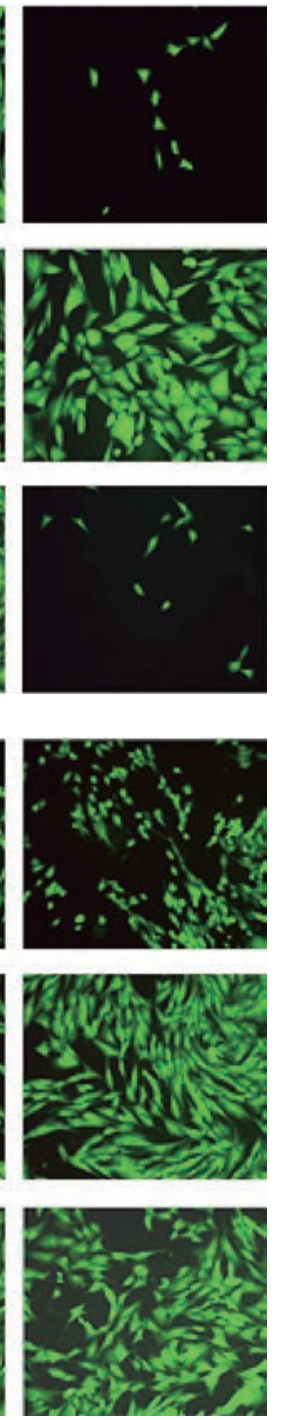

Fig. 9 Fluorescent micrographs of (a) the treated human osteosarcoma MG36 and (b) normal fibroblast BJ cells, relative to (K) the control, with the prepared scaffolds (B1: MWNTs/arginine) and B2: MWCNTs/asparagine) in comparison with ox-MWCNTs using FDA assay (Inverted microscope Axiovert 25, at magnification $10 \times$ ). 
that the main advantage of CNTs is that their structure enhances direct uptake through the cellular membrane without any detrimental effect on the cell's biological functionality [86]. In MG63 cells, 24 hours-exposure to MWCNTs resulted in increased cell viability compared to the untreated cells except cells treated with $200 \mu \mathrm{g} /$ mL ox-MWCNT B1 samples. After 48 hours-exposure to nanotubes, B1 and B2-treated MG63 cells showed increased $\mathrm{OD}$ values while the proliferation values of ox-MWCNT-treated cells were similar to those of untreated control cells.

Further analysis of the overall cell morphology reveals that MWCNT with concentrations in the range of $1-100 \mu \mathrm{g} / \mathrm{mL}$ did not induce significant morphological changes in both MG63 and BJ cells, as demonstrated in Fig. 9. The cells exhibited a normal morphology, spread and proliferated well and formed a monolayer. The highest studied concentration of 200 $\mu \mathrm{g} / \mathrm{mL}$ of all tested MWCNTs formulations however, was found to exert an adverse effect, especially in MG63 cells, by rounding the cells and reducing the number of viable cells. In BJ cells, only ox-MWCNT with a $200 \mu \mathrm{g} / \mathrm{mL}$ concentration demonstrated some cytotoxic effect, suggesting that osteoblastic MG63 cells are more responsive to MWCNTs exposure than normal fibroblastic BJ cells. Again, the highest concentrations of all MWCNTs samples induced inhibition of proliferation of osteosarcoma MG63 cells. Our results are in contrast to Luo et al., who observed neither alteration in cell morphology nor decrease in cell viability of macrophages exposed 24 hours to oxidized MWCNTs with concentrations from 0.2 to $400 \mu \mathrm{g} / \mathrm{mL}$ [87]. Presumably, the detected a higher cytotoxic potency of the $200 \mu \mathrm{g} / \mathrm{mL}$ oxidized MWCNTs in comparison to B1 and B2 is related to oxidative stress-induced from MWCNTs, although additional experiments are required to identify the exact mechanisms of action.

\section{Conclusions}

The functionalization of ox-MWCNTs using $\mathrm{L}(+)$ Arg or Asp amino acids via sol-gel technique has been investigated. It has been demonstrated that the different amino acids can promote the bone-bonding ability after soaking in SBF for 7 days at $37^{\circ} \mathrm{C}$. The results of FTIR-ATR, XRD, TGA, TEM and particle size distribution analysis are helpful to better understand the physico-chemical properties of the obtained scaffolds. Also, the elemental analysis as well as the calcium content using SEM-EDX and atomic absorption analysis, respectively, were proved the formation of the apatite layer at the surface of the immersed scaffolds. In general, independent of the type of amino acid used for modification of ox-MWCNTs (Arg or Asp), a positive effect of functionalized MWCNTs on the viability and growth of osteoblast-like cells and fibroblast cells was detected. Thus, it can be concluded that MWCNT functionalized by the sol-gel method held great potential in the field of nanobiotechnology and nanomedicine.

\section{Acknowledgments}

The authors wish to thank The Egyptian Academy of Scientific Research \& Technology, Cairo, Egypt (ASRT) for financial supporting of this work according to the Bilateral Joint Project Funding with the Bulgarian Academy of Sciences, Sofia, Bulgaria (BAS) 2019/2021.

\section{Funding}

The authors disclosed receipt of the following financial support for the research, authorship, and publication of this article: This work was supported by the Egyptian Academy of Scientific Research and Technology, Cairo, Egypt, 2019-2022.

\section{Conflicts of Interests}

The authors declare no conflict of interest.

\section{References}

[1] S. Mallakapour, A. Zadehnazari. Functionalization of multi-wall carbon nanotubes with amino acid and its influence on the properties of thiadiazol bearing poly(amide-thioester-imide) composites. Synthetic Metals 2013, 169: 1-11.

[2] S. Mallakapour, S. Soltanian, Functionalized multiwall carbon nanotube reinforced poly(ester-imide) bionanocomposites containing L-leucine amino acid units. J. Polym. Res. 2014, 21: 335-342.

[3] S. Mallakapour, S. Soltanian. Vitamin C functionalized multi-walled carbon nanotubes and its reinforcement on poly(ester-imie) nanocomposites containing L-isolucine amino acid moiety. Composite Interf. 2016, 23: 209-221.

[4] X. Ling, Y. Wei, L. Zou, S. Xu. Functionalization and dispersion of multiwalled carbon nanotubes modified with poly-lysine. Colloids Surf. A: Physico-chem Eng Aspects 2014, 443: 19-26.

[5] L.J.Cui, Y.B. Wang, Xiu J. et al. Effect of functionalization of multiwalled carbon nanotube on the curing behavior and mechanical property of multiwalled 
carbon nanotube/epoxy composites. Mater. Des. 2013, 49: 279-284.

[6] Z. Li, Z. Wu, K. Li. The high dispersion of DNAmultiwalled carbon nanotubes and their properties. Anal. Biochem. 2009, 387: 267-270.

[7] Q. Mu, W. Liu, Y. Xing et al. Protein binding by functionalized multiwalled carbon nanotubes is governed by the surface chemistry of both parties and te nanotube diameter. J. Phys. Chem. C. 2008, 112: 3300-3307.

[8] M. Sheikholeslam, M. Pritzker, P. Chen. Disoersion of multiwalled carbon nanotubes in water using ioniccomplementary peptides. Langmuir 2012, 28: 1255012556.

[9] A.A. Haroun, H.A. Taie. Preparation and rational biological evaluation of functionalized carbon nanotube with plant extracts. Proceeding at $2^{\text {nd }}$ Int. Symposium on Materials and Sustainable Development, 9-10 November, Algeria, 2015.

[10] W. Hai-Chen, C. Xueling, L. Lei, Z. Feng, Z. Yuliang. Chemistry of carbon nanotubes in biomedical applications. J. Mater. Chem. 2010, 20: 1036-1052.

[11] D. Tasis, N. Tagmatarchis, A. Bianco, M. Prato. Chemistry of carbon nanotubes. Chem. Rev. 2006, 106: 1105-1136.

[12] A.A. White, S.M. Best, I.A. Kinloch. Hydroxyapatitecarbon nanotube composites for biomedical applications: A Review. Int. J. Appl. Ceram. Technol. 2007, 4: 1-13.

[13] A.A. Haroun, F. Ayoob, E. Nashy, O. Mohamed, A. Rabi. Sol-gel preparation and in vitro kinetic release study of albendazole-immobilized MWCNTs. Egy J. Chem 2019, 63: 645-654.

[14] F. Ayoob, A.A. Haroun, E. Nashy, O. Mohamed, S. Abdelshafy, A. Rabi. Preparation, characterization and in vitro toxicity study of antiparasitic drugs loaded onto functionalized MWCNTs. Egy J. Chem 2020, 63: 38293836.

[15] A.A. Haroun, H.A. Amin, S.H. Abd El-Alim. Preparation, Characterization and In vitro biological activity of soyasapogenol B loaded onto functionalized multi-walled carbon nanotubes. Curr Bio Comp 2018, 14: 364-372.

[16] A.A. Haroun, H.A. Amin, S.H. Abd El-Alim. Immobilization and in vitro evaluation of soyasapogenol $\mathrm{B}$ onto functionalized multi-walled carbon nanotubes. IRBM 2018, 39: 35-42.

[17] H.A. Amin, A.A. Haroun. Comparative studies of free and immobilized Aspergillus flavus onto functionalized multiwalled carbon nanotubes for soyasapogenol B production. Egy Pharm J. 2017, 16: 138-143.

[18] A.A. Haroun, A.M. Elnahrawy, H.I. Abd-Alla. Sol-gel preparation and in vitro cytotoxic activity of nanohybrid structures based on multi-walled carbon nanotubes and silicate. Inorg Nano-Metal Chem 2017, 47: 1023-1027.

[19] A.A. Haroun, H.A. Taie. Cytotoxicity and antioxidant activity of beta vulgaris extract released from grafted carbon nanotubes based nanocomposites. Macromolecular Symposia 2014, 337: 25-33.

[20] B. Zhao, H. Hu, S.K. Mandal, R.C. Haddon. A bone mimic based on the self-assembly of hydroxyapatite on chemically functionalized single-walled carbon nanotubes. Chem. Mater. 2005, 17: 3235-3241.

[21] M. Świętek, A. Brož, J. Tarasiuk, S. Wroński, W. Tokarz, A. Kozieł, M. Błażewicz, L. Bačáková. Carbon nanotube/ iron oxide hybrid particles and their PCL-based 3D composites for potential bone regeneration. Mater. Sci. Eng. C 2019, 104: 109913.

[22] C. Wang, B. Yu, Y. Fan, R.W. Ormsby, H.O. McCarthy, N. Dunne, X. Li, Incorporation of multi-walled carbon nanotubes to PMMA bone cement improves cytocompatibility and osseointegration. Mater. Sci. Eng. C 2019, 103: 109823.

[23] S. Mombini, J. Mohammadnejad, B. Bakhshandeh,
A. Narmani, J. Nourmohammadi, S. Vahdat, S. Zirak. Chitosan/PVA/CNT nanofibers as electrically conductive scaffolds for cardiovascular tissue engineering. Int. J. Biol. Macromol. 2019, 140: 278-287.

[24] R. Teixeira-Santos, M. Gomes, L.C. Gomes, F.J. Mergulhao. Antimicrobial and anti-adhesive properties of carbon nanotube-based surfaces for medical applications: a systematic review. iScience 2020, 24: 102001.

[25] B. Song, Z. Zeng, G. Zeng, J. Gong, R. Xiao, M. Chen, X Tang, S. Ye, M. Shen. Effects of hydroxyl, carboxyl, and amino functionalized carbon nanotubes on the functional diversity of microbial community in riverine sediment. Chemosphere 2021, 262: 128053.

[26] L. Liu, B. Yang, L.Q. Wang, J.P. Huang, W.Y. Chen, Q. Ban, Y. Zhang, R. You, L. Yin, Y.Q. Guan. Biomimetic bone tissues engineering hydrogel scaffolds constructed using ordered CNTs and HA induce the proliferation and differentiation of BMSCs. J. Mater. Chem. B 2020, 8: 558.

[27] K.D. Patel, T.H. Kim, N. Mandakhbayar, R. Singh, J.H. Jang, J.H. Lee, H.W. Kim. Coating biopolymer nanofibers with carbon nanotubes accelerates tissue healing and bone regeneration through orchestrated cell- and tissueregulatory responses. Acta Biomaterialia 2020, 108: 97110.

[28] B. Huang, C. Vyas, J.J. Byun, M. El-Newehy, Z. Huang, P.J. Da Silva Bartolo. Aligned multi-walled carbon nanotubes with nanohydroxyapatite in a 3D printed polycaprolactone scaffold stimulates osteogenic differentiation. Mater Sci Eng C 2020, 108: 110374.

[29] N. Anzar, R. Hasan, M. Tyagi,; N. Yadav, J. Narang. Carbon nanotube-A review on Synthesis, Properties and plethora of applications in the field of biomedical science. Sensors Int. 2020, 1: 100003.

[30] A Bagherzade, M. Jamshidi. Thermo-mechanical properties of epoxy nanocomposites incorporating amino acid and acid functionalized multi-walled carbon nanotubes. J. Composite Mater 2020, 54: 1847-1861.

[31] H. Xin, X. Xiaoling, B. Guangxu, Y. Yunjun. Studies on the effects of different multiwalled carbon nanotube functionalization techniques on the properties of biobased hybrid non-isocyanate polyurethane. RSC Adv. 2020, 10: 2180.

[32] H. Ravanbakhsh, G. Bao, N. Latifi, L.G. Mongeau. Functionalized carbon nanotube-based composite hydrogels for vocal fold tissue engineering: biocompatibility, rheology, and swelling. Mater Sci Eng C Mater Biol Appl. 2019, 103: 109861.

[33] M.B. Ebrahim-Habibi, M. Ghobeh, F.A. Mahyari,. H. Rafii-Tabar, P. Sasanpour. An investigation into noncovalent functionalization of a single-walled carbon nanotube and a graphene sheet with protein G: A combined experimental and molecular dynamics study. Scientific Reports 2019, 9: 1273.

[34] R. Rahim Ghadari, A. Kashefi. Amino acid functionalized single-wall carbon nanotubes in thermoresponsive drug delivery systems: A Computational Study. Chem Select 2019, 4: 1516-1524.

[35] M. Tanaka, K. Aoki, H. Haniu, T. Kamanaka, T. Takizawa, A. Sobajima, K. Yoshida, M. Okamoto, H. Kato, N. Saito. Applications of carbon nanotubes in bone regenerative medicine. Nanomaterials 2020, 10: 659.

[36] T.M. Hadi, S.S. Sara, S. Faeze. Preparation and evaluation of polycaprolactone/amine functionalized carbon nanotube electrospun nanocomposite scaffold containing mesenchymal stem cells for use in hard tissue engineering. J. Adv Mater Technol 2020, 8: 19-30.

[37] B. Huang. Carbon nanotubes and their polymeric composites: the applications in tissue engineering. Biomanufacturing Rev 2020, 5: 3. 
[38] J.H. George, M.S. Shaffer, M.M. Stevens. Investigating the cellular response to nanofibrous materials by use of a multiwalled carbon Na-nanotube model. J. Exp. Nanosci. 2006, 1: 1-12.

[39] L.P. Zanello, B. Zhao, H. Hu, R.C. Haddon. Bone cell proliferation on carbon nanotubes. Nano Lett. 2006, 6: 562-567.

[40] D. Pantarota, M. Prato, A. Bianco. Translocation of bioactive peptides across cell membrane by carbon nanotubes. Chem. Commun. 2004, 1: 16-17.

[41] C.M. Sayes, J.D. Fortner, W. Guo, D. Lyon, The differential cytotoxicity of water soluble fullerenes. Nano Lett. 2004, 4: 1881-1887.

[42] M.F.L. De Volder, S.H. Tawfick, R.H. Baughman et al. Carbon nanotubes: present and future commercial applications. Science 2013, 339; 535-539.

[43] S.T. Yang, X. Wang, G; Jia et al. Long-term accumulation and low toxicity of single-walled carbon nanotubes in intravenously exposed mice. Toxicology Lett. 2008, 181: 182-189.

[44] R. Singh, D. Pantarotto, L. Lacerda, G. Pastorin, C. Klumpp, M. Prato, A. Bianco, K. Kostarelos, Tissue biodistribution and blood clearance rates of intravenously administrated NT radiotracers. Proc. Natl. Acad. Sci. 2006, 103: 3357-3362.

[45] A.A Haroun, B.M. Zaki, M. Shalash, R.A. Morsy. Preparation and histological study of multiwalled cacrbon nanotubes bone graft in management of class II furcation defects in dogs. Open Access Macedonian J Med. Sci. 2018, 7: 3634-3641.

[46] A.A Haroun, A.H. Neamat, S.A. Nasry. Histological study of novel bone grafts based on ß-cyclodextrin/ hydroxyapatite for class II furcation defects in dogs. $J$. Appl Sci Res 2013, 9: 3820-3833.

[47] A.A Haroun, A.H. Mossa, S.M. Mohafrash. Preparation and biochemical evaluation of functionalized multiwalled carbon nanotubes with P. granatum extract. Curr Bio Comp 2019, 15: 138-144.

[48] B. Palazzo, D. Walsh, M. Iafisco, E. Foresti, L. Bertinetti et al. Amino acid synergetic effect on structure, morphology and surface properties of bio-mimetic apatite nano-crystals. Acta Biomater 2009, 5: 1241-1252.

[49] W.H. Lee, C.Y. Loo, A.V. Zavgorodny, R. Rohanizadeh. High protein adsorptive capacity of amino-acid functionalized hydroxyapatite. J Biomed Mater Res A 2011, 101: 873-883.

[50] K.P.T. ank, K.S. Chudasama, V.S. Thaker, MJ. Joshi. Cobalt doped nano hydroxyapatite: synthesis, characterization, antimicrobial and haemolytic studies. $J$ Nanopart Res 2013, 15: 1644-1654.

[51] T. Kokubo, H. Kushitani, S. Sakka, T. Kitsugi, T. Yamamuro. Solutions able to reproduce in vivo surfacestructure change in bioactive glass-ceramic A-W. $J$ Biomed Mater Res 1990, 24: 721-34.

[52] T. Kokubo. Bioactive glass ceramics: properties and applications. Biomaterials 1991, 12:155-163.

[53] H.M. Elgendy, M.E. Norman, A.R. Keaton, C.T. Laurencin. Osteoblast-like cell (MC3T3-E1) proliferation,on bioreodible polymers: An approach towards the development of bone-bioreodible polymer composite material. Biomater 1993, 14: 263-269.

[54] K.A. Athanasiou, G.G. Niederauer, C.M. Agrawal. Sterilization, toxicity, biocompatibility and clinical applications of polylactic acid/polyglycolic acid copolymers. Biomater 1996, 17: 93-102.

[55] TA. Horbett. The role of adsorbed proteins in animal cell adhesion. Coll Surf: Biointerf 1994, 2: 225-240.

[56] D. Puleo, R. Bizios. Formation of focal contacts by osteoblasts cultured on orthopedic biomaterials. J Biomed Mater Res 1992, 26: 291-301.
[57] D.T. Haider, D.S. Ahmed., M.R. Mohamed, A.J. Haider Modification of functionalized multi-walled carbon nanotubes by olive oil as economic method for bacterial capture and prevention. Biosci. Biotech Res. Asia 2017, 1513.

[58] A.A. Haroun, A.M Elnahrawy, P. Maincent, Enoxaparinimmobilized poly(caprolactone)-based nanogels for sustained drug delivery systems. Pure Appl. Chem. 2014, 86: 691.

[59] T. Kokubo, H. Takadama, How useful is SBF in predicting in vivo bone bioactivity? J Biomater 2006, 27: 29072915.

[60] A. Oyane, H.M. Kim, T. Furuya, T. Kokubo, T. Miyazaki, T. Nakamura, Preparation and assessment of revised simulated body fluids. J. Biomed. Mater. Res. 2003, 65A: 188-195.

[61] H.J. Lee, S.J. Oh, J.Y. Choi, J. Kim, L.S. Han, J.B. Back. In situ synthesis of poly(ethylene terephthalate) (PET) in ethylene glycol containing terephthalic acid and functionalized multiwalled carbon nanotubes (MWNTs) as an approach to MWNT/PET nanocomposites. Chem. Mater. 2005, 17: 5057-5064.

[62] F. Avilés, J.V. Cauich-Rodríguez, J.A. RodríguezGonzález, A. May-Pat, Oxidation and silanization of MWCNTs for MWCNT/vinyl ester composites. eXPRESS Polym Lett 2011, 5: 766-776.

[63] S. Goyanes, G.R. Rubiolo, A. Salazar, A. Jimeno, M.A. Corcuera, I. Mondragon, Carboxylation treatment of multiwalled carbon nanotubes monitored by infrared and ultraviolet spectroscopies and scanning probe microscopy. Diamond Related Mater 2007, 16: 412-417.

[64] E.J. Gomes, J.A. Lima, P.T.C. Freire, G.S Pinheiro, F.F. de Sousa, C.M.R. Remédios, Effect of Fe (III) on L-asparagine monohydrate investigated under low-and high-temperature conditions. Spectrochimica Acta Part A: Mol Biomol Spectroscopy 2020, 241: 118643.

[65] E. Courvoisier, P.A. Williams, G.K. Lim, C.E. Hughes, K.M. Harris, The crystal structure of L-arginine. Chem. Commun. 2012, 48: 2761-2763.

[66] Y.W. Hsu, C.C. Wu, S.M. Wu, C.C. Su, Synthesis and propertie of carbon nanotube-grafted silica nanoarchitecture-reinforced poly(lactic acid). Materials 2017, 10: 829-844.

[67] S. Mallakpour, A. Abdolmaleki, S. Borandeh, L-phyenylalanine amino acid functionalized multiwalled carbon nanotube (MWCNT) as reinforced filler for improving mechanical and morphological properties of poly(vinyl alcohol) MWCNT composite. Prog. Org. Coat. 2014, 77: 1966-1971.

[68] AA. Haroun, H.M. Ahmed, E.F. Ahmed, Functionalized multi-walled carbon nanotubes as emerging carrier for biological applications. Proceedings of the 5th World Congress on New Technologies (NewTech'19) Lisbon, Portugal, August 18-20, Paper No. ICNFA 106 (2019).

[69] J.M. Berg, A. Romoser, N. Banerjee, R. Zebda, C.M. Sayes, The relationship between $\mathrm{pH}$ and zeta potential of $\sim 30 \mathrm{~nm}$ metal oxide nanoparticle suspensions relevant to in vitro toxicological evaluations. Nanotoxicology 2009, 3: 276-283.

[70] C.F. Yang, W.C. Hsu, S.M. Wu, C.C. Su, Elucidating how surface functionalization of multiwalled carbon nanotube affects nanostructured MWCNT/Titania hybrid material. $J$. Nanomater. 2015.

[71] Y.C. Hsieh, Y.C. Chou, C.P. Lin, T.F.Hsieh, C.M. Shu, Thermal analysis of multi-walled carbon nanotubes by Kissinger's corrected kinetic equation. Aerosol Air Qual. Res. 2010, 10: 212-218.

[72] M.C. Chang, C.C. Ko, W.H. Douglas, Preparation of hydroxyapatite-gelatin nanocomposite. Biomaterials 2003, 24: 2853. 
[73] M.C. Chang, J. Tanaka, FT-IR study for hydroxyapatite/ collagen nanocomposite cross-linked by glutaraldehyde. Biomaterials 2002, 23: 4811-4818.

[74] P. Zhu, Y. Masuda, K. Koumoto, The effect of surface charge on hydroxyapatite nucleation Biomaterials 2004, 25: 3915-3921.

[75] A.A. Haroun, V. Migonney, Synthesis and in vitro evaluation of gelatin/hydroxyapatite graft copolymers to form bionanocomposites. Int J Biol Macromol 2010, 46: 310-316.

[76] A.A. Haroun, H.H. Beherei, M.A. Abd El-Ghaffar, Preparation, characterization and in vitro application of composite films based on gelatin and collagen from natural resources. J Appl Polym Sci 2010, 116: $2083-$ 2094.

[77] M.S. Abdel-Hamid, M.W. Saad, G.A. Badawy, H.A. Hamza, A.A. Haroun. Synthesis and examination of hydroxyapatite nanocomposites based on alginate extracted by Azotobacter chroococcum new strain MWGH-ShKB invitro. Bioscience Res 2018, 1: 32933306.

[78] L.L. Hench. Bioactive materials: The potential for tissue regeneration. J Biomed Mater Res 1998, 41: 511.

[79] T. Miyazaki, M. Imamura, E. Ishida, M. Ashizuka, C. Ohtsuki, Apatite formation abilities and mechanical properties of hydroxyethylmethacrylate-based organicinorganic hybrids incorporated with sulfonic groups and calcium ions. J. Mater. Sci. Mater. Med. 2009, 20: $157-$ 161

[80] L. Ding, J. Stilwell, T. Zhang, et al. Molecular characterization of the cytotoxic mechanism of multiwall carbon nanotubes and nano-onions on human skin fibroblast. Nano Lett 2005, 5: 2448-2464.

[81] A. Magrez, S. Kasas, V. Salicio, et al. Cellular toxicity of carbon-based nanomaterials. Nano Lett 2006, 6: 11211125.

[82] L. Zhu, D.W. Chang, L. Dai, et al. DNA damage induced by multiwalled carbon nanotubes in mouse embryonic stem cells. Nano Lett 2007, 7: 3592-3597.

[83] P.P. Fu, Q. Xia, H.M. Hwang, P.C. Ray, H. Yu, Mechanisms of nanotoxicity: Generation of reactive oxygen species. J. Food Drug Analys 2014, 22: 64-75.

[84] E. Aldieri, I. Fenoglio, F. Cesano, E. Gazzano, G. Gulino, D. Scarano, A. Attanasio, G. azzucco, D. Ghigo, B. Fubini, The role of iron impurities in the toxic effects exerted by short multiwalled carbon nanotubes (MWCNT) in murine alveolar macrophages. J. Toxicol. Environ. Health A 2013, 76: 1056-1071.

[85] M. Allegri, D.K. Perivoliotis, M.G. Bianchi, M. Chiu, A. Pagliaro, M.A. Koklioti, T.A. Trompeta, E. Bergamaschi, O. Bussolati, C.A. Charitidis. Toxicity determinants of multi-walled carbon nanotubes: The relationship between functionalization and agglomeration. Toxicology Reports 2016, 3: 230-243.

[86] P.M. Costa, M. Bourgognon, T.W. Wang, K.T. Al-Jamal. Functionalised carbon nanotubes: From intracellular uptake and cell-related toxicity to systemic brain delivery. J. Control Releas 2016, 241: 200-219.

[87] M. Luo, P. Chen, J. Wang, et al. The cytotoxicity of oxidized multi-walled carbon nanotubes on macrophages. Sci. China Chem. 2016, 59: 918-926.

Copyright $₫$ Ahmed Haroun, Zlatina Gospodinova, and Natalia Krasteva. This is an open-access article distributed under the terms of the Creative Commons Attribution License, which permits unrestricted use, distribution, and reproduction in any medium, provided the original author and source are credited. 